\title{
Analysis of licensed over-the-counter (OTC) antibiotics in the European Union and Norway, 2012
}

L Both $^{1}$, R Botgros ${ }^{2}$, M Cavaleri ${ }^{2}$

1. Public Health England (PHE), London, United Kingdom

2. Anti-infectives and Vaccines Office, European Medicines Agency (EMA), London, United Kingdom

Correspondence: Marco Cavaleri (Marco.Cavaleri@ema.europa.eu)

Both L, Botgros R, Cavaleri M. Analysis of licensed over-the-counter (OTC) antibiotics in the European Union and Norway, 2012. Euro Surveill. 2015;20(34):pii=30002. DOI: http://dx.doi.org/10.2807/1560-7917.ES.2015.20.34.30002

Article submitted on 16 September 2014 / accepted on 09 February 2015 / published on 27 August 2015

Antimicrobial resistance is recognised as a growing problem that seriously threatens public health and requires prompt action. Concerns have therefore been raised about the potential harmful effects of making antibiotics available without prescription. Because of the very serious concerns regarding further spread of resistance, the over-the-counter (OTC) availability of antibiotics was analysed here. Topical and systemic OTC antibiotics and their indications were determined across 26 European Union (EU) countries and Norway by means of a European survey. We identified a total of 48 OTC products containing 20 different single antibiotics and three antibiotic combinations as active substances, used mainly as topical preparations in short treatment courses. Given the relevance of these medicines and the increasing risk of antimicrobial resistance, it is important to limit the availability of OTC antibiotics and to monitor their use.

\section{Introduction}

The large majority of medicines are restricted to prescription-only-medicines (POM) status across the European Union (EU) Member States, but several medicines are being reassigned to over-the-counter (OTC) status post approval. The latter is done in response to perceived public demand for easier access to medicines and to government policies in some Member States which aim to increase the access of patients to medicines when it is safe to do so. If the safety profile is good and the risk of misuse is low, a previous POM medicine may be reclassified for sale or supply as an OTC medicine, usually under the supervision of a pharmacist $[1,2]$. The regulatory climate in some European countries appears moderately positive towards downregulation, but before a medicine can be reclassified from POM to OTC it should meet certain criteria, as listed in the European Commission's guideline on changing the classification for the supply of a medicinal product for human use [3]. This guidance facilitates the harmonisation of POM and OTC status of medicines throughout the EU; however, there are still considerable differences in Europe due to the different healthcare structures and policies (including the extent of pharmacist supervision for OTC medicines), reimbursement policies, and cultural differences of each Member State. Therefore, the availability of OTC medicines varies in the EU and products sold as POM in certain countries can be obtained as OTC medicines in others.

As risk minimisation is an important criterion for some OTC products such as antibiotics, they are usually dispensed under the supervision of a pharmacist, as opposed to buying them 'off the shelf' [4]. Switching to OTC status generally makes a medicine more readily available and is also often associated with a shift of costs from the public purse to the private $[1,2]$. For pharmaceutical companies, there are potentially attractive aspects to apply for POM to OTC switches, e.g. some advertising restrictions for pharmaceuticals are removed (as European law allows companies to advertise OTC products directly to consumers).

Bacterial infections often present acutely and patients may therefore benefit from easier and quicker access to certain antibacterials. This could potentially shorten the period of illness and reduce both the length of symptoms and infectivity, as opposed to delaying the treatment while waiting to see a physician [5]. However, in light of the current spread of antimicrobial resistance, making antibiotics available as OTC medicines is of concern and might potentially lead to their mis- and overuse [6]. Indeed, the continuous rise of antimicrobial resistance and the concomitant lack of new therapeutic options to fill the gap represent major threats to public health that call for a variety of urgent actions in order to preserve as much as possible the currently available armamentarium. Incorrect use or overuse of antibiotics may not only reduce their benefits for the individual patients but may also lead to treatment failures in the community due to emerging resistance $[7,8]$. 
TABLE 1

Active substances of single (A) and combination (B) OTC antibiotics and number of EU/EEA countries where OTC antibiotics are available, 2012

\begin{tabular}{|l|c|}
\hline A & EU/EEA countries (n) \\
\hline Single antibiotics & 10 \\
\hline Tyrothricin & 8 \\
\hline Fusafungine & 3 \\
\hline Neomycin & 3 \\
\hline Chloramphenicol & 2 \\
\hline Gentamicin & 2 \\
\hline Oxytetracycline & 2 \\
\hline Nifuroxazide & 1 \\
\hline Bacitracin & 1 \\
\hline Chlortetracycline & 1 \\
\hline Sulfamethizole & 1 \\
\hline Sulfanilamide & 1 \\
\hline Nitrofural & 1 \\
\hline Metronidazole & 1 \\
\hline Sulfadimidine & 1 \\
\hline Primycin & 1 \\
\hline Ciprofloxacin & 1 \\
\hline Fusidic acid & 1 \\
\hline Azithromycin & 1 \\
\hline Methenamine & \\
\hline Framycetin & EU/EEA countries (n) \\
\hline B & 3 \\
\hline Combination products & 1 \\
\hline Bacitracin/neomycin combination & 1 \\
\hline $\begin{array}{l}\text { Oxytetracycline/polymyxin } \\
\text { Combination }\end{array}$ & 1 \\
\hline Neomycin/sulfathiazole & \\
\hline combination & 1 \\
\hline
\end{tabular}

EU/EEA: European Union/European Economic Area; OTC: over-the-counter.

a Systemic antibiotics.

Thus, it is no surprise that concerns have been raised about the potential harmful effects of making antibiotics available without prescription [9]. The greatest concern is that the possible risk of societal harm may outweigh the potential benefits to individual patients due to the emergence of antimicrobial resistance.

Importantly, OTC availability generally appears to lead to increases in use: in a Swedish study assessing 16 (non-antibiotic) drugs, OTC availability was associated with a $36 \%$ sales increase [10]. Moreover, in a British study, the OTC availability of antibiotic eye drops containing chloramphenicol was associated with a $48 \%$ sales increase $[11,12]$. Further investigation is needed to determine if these increases in consumption will have any effects on antimicrobial resistance.

In the resolution of 11 December 2012 on the Microbial Challenge - Rising threats from Antimicrobial
Resistance, the European Parliament "calls on the Member States to raise awareness against over-thecounter and illegal sales of antimicrobials in both the human health and the veterinary sector' [13]. Based on the above concerns around antibacterials' use, a survey across the EU Member States to determine the amount of available OTC antibiotics has been conducted. The main objective of this analysis was to get an accurate picture about which antibiotics are available as OTC medicines in the EU and to characterise them in terms of their antibiotics classes, presentation as single/combination products, dosage, pharmaceutical form, and systemic/topical administration. In developing this report, it was decided to concentrate solely on antibiotics while it was recognised at the same time that OTC medicines against fungal, viral and parasitical infections are also available.

\section{Methods}

A questionnaire was prepared by the European Medicines Agency (EMA) to investigate the availability of OTC antibiotics across the EU and Norway. The questionnaire was sent by email to the National Competent Authorities (NCAs), i.e. the national regulatory authorities for medicinal products, of the then 27 EU Member States and of Norway, a member of the European Economic Area (EEA). The questionnaire asked for details of the active substance, of the main indication(s), and - if available - of increases in sales/ usage and antimicrobial resistance. The replies were edited for length and clarity and antifungals/antivirals/ antiseptics were removed from the list where necessary, e.g. products containing (di-)propamidine isetionate were not included. The tables hereafter include topical and systemic antibiotic products (with brand names where available) and main indications for OTC use. Of note, certain antibiotics, including sulfaguanidine (Enteropathyl, Sulfadiar, Litoxol) in France or certain framycetin, ofloxacin and rifamycin formulations in Cyprus, are authorised as OTC but are not marketed and were therefore excluded from this analysis. A list of antibiotics was generated and - where possible preparations were combined to account for different brand names and different presentations (e.g. ointment or cream), resulting in a total of 48 antibiotic pharmaceutical forms. An analysis of the number of active substances, used either alone or in combination, was undertaken. To analyse regional differences in OTC availability across Europe, the countries were grouped into northern/eastern/southern/western European countries according to their classification by the EU Publications Office [14].

\section{Results}

In October 2012, a questionnaire was circulated to the EU Member States and Norway. Twenty-six of 28 targeted countries responded and Excel tables listing OTC antibiotics and indications were received by EMA in January 2013. The 48 identified antibiotic pharmaceutical forms (averaging 1 -2 OTC pharmaceutical forms per country) contained 20 different active substances 
TABLE 2A

Topical OTC antibiotics and indications in the EU Member States and Norway, 2012

\begin{tabular}{|c|c|c|}
\hline EU/EEA country & OTC antibiotics & Indications \\
\hline \multicolumn{3}{|l|}{ Northern Europe } \\
\hline Denmark & NA & NA \\
\hline Estonia & Fusafungine (Bioparox), nasal/oral aerodispersion & $\begin{array}{l}\text { Topical treatment of upper respiratory tract infections caused by } \\
\text { microorganisms susceptible to fusafungine. }\end{array}$ \\
\hline Finland & NA & NA \\
\hline \multirow{3}{*}{ Latvia } & $\begin{array}{l}\text { 1. Chloramphenicol, ointment } \\
\text { 2. Chloramphenicol combination (including methyluracil), } \\
\text { ointment }\end{array}$ & $\begin{array}{l}\text { 1. Topical treatment of infected wounds in the reparative (tissue } \\
\text { regeneration) phase, long indelible trophic ulcers, II-III degree burns and } \\
\text { bedsores. } \\
\text { 2. Topical treatment of infected wounds in the purulent-necrotic phase. }\end{array}$ \\
\hline & Nitrofural, solution for local use & Topical treatment of bacterial infections of the skin and mucosa. \\
\hline & $\begin{array}{l}\text { Tyrothricin combination (including lidocaine hydrochloride, } \\
\text { chlorhexidine digluconate), lozenges }\end{array}$ & $\begin{array}{l}\text { Recommended for short-term relief of symptoms of oral and throat } \\
\text { inflammation. Prevention of infections before/during mouth and throat } \\
\text { operations (tooth extractions, gum surgical treatment). }\end{array}$ \\
\hline Lithuania & $\begin{array}{l}\text { Tyrothricin combination (including lidocaine hydrochloride, } \\
\text { chlorhexidine digluconate), lozenges }\end{array}$ & $\begin{array}{l}\text { Short-term relief of symptoms of oral and throat inflammation. Prevention } \\
\text { of infections before/during mouth and throat operations. }\end{array}$ \\
\hline Norway & $\begin{array}{l}\text { Bacitracin combination (including chlorhexidine) (Bacimycin), } \\
\text { ointment }(500 \mathrm{IE} / \mathrm{g} / 5 \mathrm{mg} / \mathrm{g})\end{array}$ & $\begin{array}{l}\text { Local treatment of superficial skin infections caused by Gram-positive and } \\
\text { Gram-negative pathogenic bacteria. Impetigo, paronychia, furunculosis, } \\
\text { infected wounds and eczema. Prophylactic use for superficial burns. }\end{array}$ \\
\hline Sweden & Metronidazole (topical) & Treatment of rosacea. \\
\hline \multicolumn{3}{|l|}{ Eastern Europe } \\
\hline \multirow[b]{2}{*}{ Bulgaria } & Fusafungine (Bioparox), nasal/oral aerodispersion & $\begin{array}{l}\text { Treatment of infections and inflammatory diseases of the respiratory } \\
\text { tract (rhinitis, rhinopharyngitis, tracheitis, laryngitis, tonsillitis, post- } \\
\text { tonsillectomy and sinusitis) in adults and children aged over } 30 \text { months. }\end{array}$ \\
\hline & $\begin{array}{l}\text { Tyrothricin (Trachisan) combination (including lidocaine } \\
\text { hydrochloride, chlorhexidine digluconate), lozenges }\end{array}$ & $\begin{array}{l}\text { Local treatment of oral cavity and throat inflammations, such as stomatitis, } \\
\text { gingivitis, periodontitis, glossitis, tonsillitis, pharyngitis, dysphagia. } \\
\text { Prophylaxis of pre- and post- surgery infections of oral cavity and throat } \\
\text { (tooth extraction, surgical treatment of gums, tonsillectomy). }\end{array}$ \\
\hline Czech Republic & Fusafungine (Bioparox), nasal/oral aerodispersion & $\begin{array}{l}\text { Local treatment of inflammations and infections of pharyngeal and } \\
\text { respiratory mucosa - in rhinitis, sinusitis, rhinopharyngitis, laryngitis, } \\
\text { pharyngitis, tonsillitis, tracheitis, bronchitis and after tonsillectomy; for } \\
\text { children over } 30 \text { months of age and adults. }\end{array}$ \\
\hline \multirow{5}{*}{ Hungary } & $\begin{array}{l}\text { Fusafungine (Bioparox), nasal/oral aerodispersion ( } 50 \mathrm{mg} / 10 \\
\mathrm{ml} \text { ) }\end{array}$ & $\begin{array}{l}\text { Treatment of infections and inflammations of upper airways (rhinitis, } \\
\text { rhinopharyngitis, tracheitis, laryngitis, tonsillitis, condition following } \\
\text { tonsillectomy, sinusitis) for adults or children aged over } 30 \text { months. }\end{array}$ \\
\hline & Gentamicin (Gentamicin-Wagner), ointment (1mg/g) & Skin infections caused by gentamicin sensitive bacteria. \\
\hline & $\begin{array}{l}\text { 1. Oxytetracycline (Tetran), ointment }(10 \mathrm{mg} / \mathrm{g}) \\
\text { 2. Oxytetracycline (Tetran), powder for external use }\end{array}$ & $\begin{array}{l}\text { 1. Skin infections caused by oxytetracyclin sensitive bacteria } \\
\text { 2. Shallow wound infections caused by oxytetracyclin sensitive bacteria. }\end{array}$ \\
\hline & Primycin (plus lidocaine) (Ebrimycin), gel & $\begin{array}{l}\text { Prevention of bacterial infection of fresh, shallow lesions, burns, } \\
\text { lacerations, local treatment of lesions infected by primycin-sensitive } \\
\text { bacteria, lacerations, post-operational wounds, trophic ulcers (e.g.: } \\
\text { ulcuc cruris, decubitus), necrotic open suppurations (e.g.: gangraena, } \\
\text { fistula, chronic osteomyelitis, abcess), superficial and deep suppurations } \\
\text { (e.g.: folliculitis, acne vulgaris, impetigo contagiosa, ecthyma, furuncle, } \\
\text { carbuncle, panaritium). }\end{array}$ \\
\hline & $\begin{array}{l}\text { Tyrothricin (Dorithricin) combination (including benzalkonium } \\
\text { chloride), lozenges }\end{array}$ & $\begin{array}{l}\text { Symptomatic treatment of infections of the mouth and pharynx } \\
\text { accompanied by swallowing difficulties and sore throat. }\end{array}$ \\
\hline \multirow{3}{*}{ Romania } & $\begin{array}{l}\text { Bacitracin and neomycin combination (Baneocin), cutaneous } \\
\text { powder and ointment }\end{array}$ & Infections caused by neomycin and/or bacitracin-susceptible organisms. \\
\hline & $\begin{array}{l}\text { Fusafungine (Bioparox), nasal/oral aerodispersion } \\
\text { (50mg/10ml) }\end{array}$ & $\begin{array}{l}\text { Treatment of infections and inflammatory diseases of the upper respiratory } \\
\text { tract (rhinitis, rhinopharyngitis, tonsillitis, tracheitis, post-tonsillectomy, } \\
\text { laryngitis, tracheitis, sinusitis) for adults and children aged over } 30 \\
\text { months. }\end{array}$ \\
\hline & $\begin{array}{l}\text { Tyrothricin (Trachisan) combination (including lidocaine } \\
\text { hydrochloride, chlorhexidine digluconate), lozenges }\end{array}$ & $\begin{array}{l}\text { Local treatment of oral cavity and throat inflammations (stomatitis, } \\
\text { gingivitis, tonsillitis) pharyngitis, dysphagia. Infection of upper respiratory } \\
\text { tract (pharyngitis, dysphagia). For prophylaxis of post-surgery infections of } \\
\text { oral cavity and throat (tooth extraction, tonsillectomy). }\end{array}$ \\
\hline Slovakia & Fusafungine (Bioparox), nasal/oral aerodispersion & $\begin{array}{l}\text { Local treatment of inflammations and infections of oropharyngeal and } \\
\text { respiratory mucosa in rhinitis, sinusitis, rhinopharyngitis, laryngitis, } \\
\text { pharyngitis, tonsillitis, post tonsillectomy, tracheitis, bronchitis. }\end{array}$ \\
\hline Slovenia & NA & NA \\
\hline
\end{tabular}

EU/EEA: European Union/European Economic Area; NA: not available (no OTC antibiotics available); OTC: over-the-counter. 
TABLE 2B

Topical OTC antibiotics and indications in the EU Member States and Norway, 2012

\begin{tabular}{|c|c|c|}
\hline EU/EEA country & OTC antibiotics & Indications \\
\hline \multicolumn{3}{|c|}{ Southern Europe } \\
\hline Cyprus & Neomycin & Dermatological and ophthalmological use. \\
\hline Greece & Neomycin (Pulvo-47), aerosol for topical application & Local use for prophylaxis in post-surgical and other injuries. \\
\hline Italy & $\begin{array}{l}\text { Bacitracin and neomycin antibiotic combination (Cicatrene), } \\
\text { cream and cutaneous powder }\end{array}$ & $\begin{array}{l}\text { Superficial skin infections (folliculitis, furunculosis, small burns and } \\
\text { infected wounds). }\end{array}$ \\
\hline Malta & NA & NA \\
\hline \multirow[b]{2}{*}{ Portugal } & 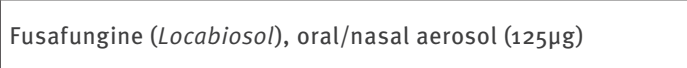 & $\begin{array}{l}\text { Local treatment of diseases of the upper respiratory tract } \\
\text { (rhinopharyngitis). }\end{array}$ \\
\hline & $\begin{array}{l}\text { 1. Tyrothricin (Hydrotricine) } \\
\text { 2. Tyrothricin ( } 4 \mathrm{mg} \text { ) combination (including cetylpyridinium } \\
\text { chloride } 1 \mathrm{mg} \text {, oxybuprocaine } 0.2 \mathrm{mg} \text { ) (Mebocaína Forte) }\end{array}$ & $\begin{array}{l}\text { 1. Local treatment of topical infections localised and limited to the buccal } \\
\text { mucosa and oropharyngeal. } \\
\text { 2. Local treatment of sore throat and infections of mouth and pharynx. }\end{array}$ \\
\hline \multirow{3}{*}{ Spain } & Gentamicin (Oculos Epitelizante), ointment & Treatment of ocular infections. \\
\hline & $\begin{array}{l}\text { Neomycin (Blastoestimulina ointment, Edifaringén tablets, } \\
\text { Phonal tablets for solution, Rinobanedif ointment, and } \\
\text { Synalar nasal) }\end{array}$ & E.g. wound healing. \\
\hline & $\begin{array}{l}\text { Tyrothricin (Anginovag solution for spraying, Bucometasana } \\
\text { tablets, Cicatral ointment, Cohortán Rectal ointment, } \\
\text { Denticelso solution, Miozets tablets, Koki tablets, Piorlis skin } \\
\text { solution, Roberfarín spray, and Viberol mouth solution) }\end{array}$ & Treatment of topical infections. \\
\hline \multicolumn{3}{|l|}{ Western Europe } \\
\hline Austria & NA & NA \\
\hline \multirow{8}{*}{ Belgium } & $\begin{array}{l}\text { Bacitracin and neomycin antibiotic combination } \\
\text { (Neobacitracine Nouvelle Formule) }\end{array}$ & $\begin{array}{l}\text { Local antibiotic treatment of infections caused by sensitive germs. } \\
\text { Treatment of skin infection. }\end{array}$ \\
\hline & Chloramphenicol (Erfa chloramphenicol) & $\begin{array}{l}\text { Local antibiotic treatment of infections caused by sensitive germs. Should } \\
\text { not be used for minor infections or for prophylaxis. }\end{array}$ \\
\hline & Chlortetracycline (Aureomycin), (1\%), ointment & Ocular infections caused by tetracycline-sensitive microorganisms \\
\hline & Framycetin (Septomixine Nouvelle Formule) & Minimisation of pain and canal disinfection. \\
\hline & $\begin{array}{l}\text { Fusidic acid: } \\
\text { 1. Fucidin crème }(2 \%) \text {, cream/Fucidin zalf ( } 2 \%) \text {, ointment } \\
\text { 2. Fucidin Intertulle }(2 \%) \text {, impregnated fabric } \\
\text { 3. Fucithalmic }(10 \mathrm{mg} / \mathrm{g}) \text {, eye drops } \\
\text { 4. Affusine }(20 \mathrm{mg} / \mathrm{g}) \text {, cream }\end{array}$ & $\begin{array}{l}\text { 1. Infections caused by Staphylococcus aureus, Streptococcus spp. Infection } \\
\text { prophylaxis. } \\
\text { 2. Infected wounds and superficial skin infections. Traumatic and surgical } \\
\text { wounds. Deep or superficial burns. } \\
\text { 3. Anterior segment eye infections caused by sensitive microorganisms. } \\
\text { 4. Treatment of non-severe, superficial, non-extensive, primary skin } \\
\text { infections caused by microorganisms sensitive to fusidic acid, especially } \\
\text { infections caused by Staphylococcus. }\end{array}$ \\
\hline & Oxytetracycline (Terra-cortril) & $\begin{array}{l}\text { Skin infections with severe inflammatory reaction, infected atopic } \\
\text { dermatitis, infected contact dermatitis. }\end{array}$ \\
\hline & $\begin{array}{l}\text { 1. Oxytetracycline (Terramycine) + polymyxine B antibiotic } \\
\text { combination, ointment } \\
\text { 2. Oxytetracycline (Terramycine) + polymyxine B antibiotic } \\
\text { combination, eye ointment }\end{array}$ & $\begin{array}{l}\text { 1. Prophylaxis and treatment of local skin infections. } \\
\text { 2. Treatment of superficial ophthalmic infections. }\end{array}$ \\
\hline & $\begin{array}{l}\text { 1. Tyrothricin combinations (Tyrothricine Lidocaine Citroen/ } \\
\text { Munt Melisana) } \\
\text { 2. Tyrothricin (Lemocin) combination (incl. } \\
\text { cetrimoniumbromide, lidocaine) }\end{array}$ & $\begin{array}{l}\text { 1. Local or adjuvant symptomatic treatment of painful mouth and throat } \\
\text { infections. } \\
\text { 2. Symptomatic treatment of inflammatory and painful infection of } \\
\text { buccopharyngeal crossroad. }\end{array}$ \\
\hline France & NA & NA \\
\hline \multirow[b]{2}{*}{ Germany } & $\begin{array}{l}\text { Fusafungine (Locabiosol), oral/nasal aerodispersion } \\
(0,5 \mathrm{mg} / 0,125 \mathrm{mg})\end{array}$ & Rhinosinusitis, Laryngitis, Rhinopharyngitis, Streptococci infections. \\
\hline & $\begin{array}{l}\text { 1. Tyrothricin (Dorithricin) combination (including } \\
\text { benzocaine, benzalkonium chloride), lozenges } \\
\text { 2.Tyrothricin (Lemocin) combination (including } \\
\text { cetrimoniumbromide, lidocaine), lozenges/oral solution } \\
\text { 3. Tyrothricin (Tyrosur), gel and powder (Micasal) }\end{array}$ & $\begin{array}{l}\text { 1. Infections of mouth and throat. } \\
\text { 2. Inflammations of mouth and throat. } \\
\text { 3. Wounds with bacterial superinfection. }\end{array}$ \\
\hline Ireland & NA & NA \\
\hline The Netherlands & NA & NA \\
\hline \multirow[t]{2}{*}{ United Kingdom } & Chloramphenicol, eye drops and eye ointment & $\begin{array}{l}\text { Treatment of acute bacterial conjunctivitis in adults and children aged } 2 \\
\text { years and over. }\end{array}$ \\
\hline & Tyrothricin, throat pastilles/lozenges & Treatment of infections of the mouth and pharynx. \\
\hline
\end{tabular}

EU/EEA: European Union/European Economic Area; NA: not available (no OTC antibiotics available); OTC: over-the-counter. 
TABLE 3

Synthetic OTC antibiotics (sulfonamide and quinolone) for topical application and their indications in European Union countries, 2012

\begin{tabular}{|l|l|l|}
\hline EU country & OTC antibiotics & Indications \\
\hline Estonia & Sulfamethizole (Sulfametizol Nycomed), eye drops (4\%) & Short-term treatment of bacterial eye infections. \\
\hline Latvia & Sulfanilamide, ointment and cutaneous powder & $\begin{array}{l}\text { Topical treatment of skin infections caused by Gram-positive or } \\
\text { Gram-negative bacteria. }\end{array}$ \\
\hline Rungary & Sulfadimidine (Septosyl), eye ointment & $\begin{array}{l}\text { Acute and chronic conjunctivitis of bacterial origin, cornea } \\
\text { infiltration and ulcer, several types of blepharitis (acute, chronic, } \\
\text { ulcerative) blepharo-conjunctivitis, hordeolum, infected eyelid } \\
\text { eczema, inflammation of the tear duct, removal of foreign body from } \\
\text { conjunctive or from cornea, prevention of infection following other } \\
\text { superficial eye interventions. }\end{array}$ \\
\hline Italy & $\begin{array}{l}\text { Neomycin and sulfathiazole antibiotic combination } \\
\text { (Streptosil neomicina), ointment and cutaneous powder } \\
\text { auricular drops, solution }\end{array}$ & $\begin{array}{l}\text { Scute and chronic external otitis of bacterial origin, with intact } \\
\text { infected wounds). } \\
\text { eczemanic membrane in adults and children in particular, infected }\end{array}$ \\
\hline
\end{tabular}

EU: European Union; OTC: over-the-counter.

(single antibiotics) and three mixtures containing multiple antibiotics (Table 1). Of these 20 active substances, eight were available in more than one Member State.

All OTC antibiotics are listed in Table 2 together with their country of availability. A total of 20 EU/EEA Member States have OTC antibiotics: 16 of these have only topical antibiotics, two have only systemic antibiotics, and another two have both topical and systemic antibiotics available on the market. The number of OTC antibiotics available in each Member State varied widely across the EU, ranging from zero to eight OTC antibiotics. No OTC antibiotics are available in Austria, Finland, Ireland, Malta, the Netherlands and Slovenia, whereas countries like Belgium and Hungary offer a relatively wide range of different OTC antibiotics (eight and five, respectively) (Table 2 ).

It has recently been reported that non-prescription antibiotics use (including non-legal use) varies between European regions, e.g. the lowest levels of non-prescription antibiotics use were observed in northern Europe (weighted non-prescription use was $3 \%$ ) while the highest levels were observed in eastern Europe (weighted non-prescription use was 30\%) [15]. To investigate whether this geographical distribution is preserved for the licensed OTC antibiotics listed here (Table 2), the EU/EEA Member States were grouped into northern/eastern/southern/western European countries. This revealed that northern European countries have the least amount of OTC antibiotics $(n=7)$. Both eastern and western Europe have a relatively high amount of OTC antibiotics ( $n=12$ in both cases) but it should be mentioned that the high numbers in western Europe were mainly due to Belgium which accounted for eight of 12 OTC antibiotics available in western European countries.
It was observed that certain antibiotics are frequently assigned to OTC status across the EU, in particular a large number of tyrothricin and fusafungine products (available in 10 and eight countries, respectively) (Table 2). Fusafungine products are available as OTC medicines in eight of the 26 EU/EEA Member States analysed here, especially in the eastern European countries (five out of six Member States). Likewise, chloramphenicol and neomycin products are more frequently available without prescription. In contrast, certain products like methenamine, metronidazole, azithromycin and nitrofural are rarely available as OTC medicines across the EU/EEA Member States.

The OTC antibiotics available in the EU belong to various antibiotic classes, e.g. tetracyclines and sulphonamides. Table 3 shows all synthetic OTC antibiotics of the sulphonamide and quinolone classes. Overall, the vast majority (20 of 23 ) of OTC single antibiotics/antibiotic mixtures identified here are solely used for topical application, with a few exceptions including oral methenamine (ATC code J01XX05), nifuroxazide (ATC code $\mathrm{A07AX03}_{3}$ and azithromycin (ATC code Jo1FA10) (Table 4). Of the 23 single antibiotics and antibiotic mixtures, 19 are used for infections of the skin, eyes, and oral/pharyngeal/respiratory mucosa, one is used for ear infections (ciprofloxacin), one is used for diarrhoea (nifuroxazide), one is used for genital infections (azithromycin), and one is used for urinary tract infections (methenamine).

\section{Discussion}

The contribution of OTC antibiotics' use to the development and spread of antimicrobial resistance genes and bacteria is not known. However, all antibiotic use - whether it is prescription or non-prescription - exerts 
TABLE 4

Systemic OTC antibiotics and their indications in European Union countries, 2012

\begin{tabular}{|l|l|l|}
\hline EU country & OTC antibiotics & Indications \\
\hline Denmark & Methenamine (Hiprex), tablets & Prophylaxis of urinary tract infections, especially for patients with a catheter. \\
\hline Slovakia & Nifuroxazide (Endiex), oral administration & $\begin{array}{l}\text { Acute diarrhoea of bacterial origin without signs of invasion; diarrhoea related } \\
\text { to the bowel dysmicrobia. }\end{array}$ \\
\hline France & Nifuroxazide (Ercefuryl and generics) & $\begin{array}{l}\text { Treatment of acute diarrhoea presumed to be of bacterial origin, in the absence } \\
\text { of suspected invasive phenomena. }\end{array}$ \\
\hline $\begin{array}{l}\text { United } \\
\text { Kingdom }\end{array}$ & Azithromycin (1g) & $\begin{array}{l}\text { Treatment of confirmed asymptomatic Chlamydia trachomatis genital infection } \\
\text { in individuals aged 16 years and over, and for the epidemiological treatment of } \\
\text { their sexual partners. }\end{array}$ \\
\hline
\end{tabular}

EU: European Union; OTC: over-the-counter.

antimicrobial selection pressure $[16,17]$. A first step in trying to assess the contribution of OTC antibiotics to emerging resistance is to investigate which and how many antibiotics are affected and whether they are administered topically or systemically. Our analysis of OTC antibiotics in the EU and Norway demonstrates that (i) only few antibiotics with OTC status are currently available across the EU and Norway (on average onetwo OTC antibiotic pharmaceutical forms/country); (ii) the large majority (20 of 23 single/combination active substances) of the OTC antibiotics identified here are solely used for topical application, except methenamine, nifuroxazide and azithromycin; (iii) overall, it is not apparent that the current situation for OTC antibiotics in the EU and Norway poses substantial risks, but further monitoring would still be warranted.

Among the critically important antibiotics defined by the World Health Organization (WHO) [18] only azithromycin, a macrolide antibiotic for the treatment of laboratory-confirmed asymptomatic genital chlamydial infections, is available in the EU as a systemic OTC medicine, and only in the United Kingdom (UK). However, it has to be recognised that appropriate safeguards are in place in this case: to avoid OTC antibiotic misuse or overuse, patients with suspected Chlamydia infection buy an approved testing kit in a UK pharmacy or online and post a urine sample to an approved laboratory [19]. If the test is positive, the patient can request azithromycin from a pharmacy. The pharmacist will ask the patient about symptoms, advice the patient on the use of azithromycin, and provide a notification slip (bearing the unique index patient identifier) for the sexual partner(s) who will be able to purchase azithromycin tablets from the pharmacy [19]. The approved testing laboratory performing the urine test must collect data on tests performed which are available for monitoring at quarterly intervals by regulatory authorities. One drawback would be that if any co-infection (e.g. gonococcal infection) is occurring, this could be missed by avoidance of general practitioner (GP) consultation with potential deleterious consequences.
Several antibiotics have been assigned from POM to OTC status fairly recently and it is currently not clear whether their OTC availability might lead to increased resistance. However, it should be noted that antimicrobial resistance has been reported for the POM counterparts of several OTC antibiotics listed in this report, e.g. widespread resistance against fusidic acid (as POM) has recently been reported in Malta [20]. It cannot be ruled out that making fusidic acid widely available as an OTC medicine could increase the risk of emerging resistance and thereby reduce its activity in other applications such as a valuable anti-staphylococcal agent to treat osteomyelitis. Despite a lack of hard evidence regarding emerging resistance resulting from the usage of OTC antibiotics - most of which are used topically - we believe it would be important that antibiotics are not made available as OTC medicines particularly if they belong to classes of agents frequently used to treat serious infections. This would possibly not preclude the option to retain a limited number of available OTC antibiotics, constituted only by well-characterised agents with no or limited prescription indications and with no cross-resistance potential to other important antimicrobials. Moreover, the use of oral OTC antibiotics (e.g. methenamine) should be limited and monitored closely.

It is important to note that there are certain conditions for OTC supply and products may be limited to specific indications with appropriate restrictions on strength, dose and pack size. Additional considerations might apply to certain OTC antibiotics, e.g. in the case of OTC azithromycin: the national usage of the product should be monitored and Periodic Safety Update Reports (PSURs) should be submitted by the Marketing Authorization (MA) holder at six monthly intervals including usage data and any available information on resistance in Chlamydia trachomatis, Neisseria gonorrhoea and other pathogens [21].

It should be mentioned that, in addition to OTC antibiotics, patients may receive antibiotics without a prescription, even if these are not legally classified as OTC medicines: antibiotics could be obtained without 
prescription illegally from pharmacies (or through the Internet), which occurs in various degrees across Europe as discussed elsewhere $[15,22,23]$. Moreover, patients sometimes take antibiotics from previous treatment courses prescribed for themselves or their family members, as described in a recent Eurobarometer [24].

Two surveys of the general population from eastern Europe were recently reported $[23,25]$. Data from Lithuania, Poland, and Romania [23] suggested that frequency of antibiotic use varied from $23 \%$ to $51 \%$. Of antibacterials used, weighted non-prescription use was $30 \%$. Of the non-prescription antibiotics, 68\% were purchased at a pharmacy and $32 \%$ were from friends, family, or home. Given these high numbers, it is important to reduce the availability of non-prescription antibiotics. This is in line with the European Parliament's resolution to raise awareness against OTC and illegal sales of antimicrobials [13]. Non-prescription use has been speculated to play a role in selecting and maintaining high levels of community antimicrobial resistance [25-28]. Although self-medication antibiotics are usually associated with short treatment courses [29-30] community antimicrobial resistance was nevertheless common in various studies that examined communities with frequent use of non-prescription antimicrobials [31-33].

Because the OTC status of individual antibiotics has so far been decided at the national and not the European level, it is no surprise that there is not much overlap between countries concerning the type and number of OTC antibiotics. Reasons for these differences might include national healthcare policies, reimbursement policies, and the different roles of pharmacists in dispensing OTC antibiotics to patients. As shown by the data generated by the European Surveillance for Antimicrobial Consumption Network (ESAC-Net), the use of systemic antimicrobials varies greatly between EU Member States [34]. As such, it is expected that a similar national variation in use would apply to OTC antibiotics. While the use of systemic antibiotics is regularly monitored across Europe by ESAC-Net, there is no European network in place for monitoring the use of the various OTC antibiotics licensed across the EU, which seems justified based on the very limited number of OTC antibiotics currently available in the EU. Although installing such a network for OTC antibiotics might perhaps be considered useful in the future, a more effective approach would be to limit the number of OTC antibiotics as much as possible in the first place.

The efficacy of antibiotics needs to be preserved - by all means necessary - and it could therefore be argued that antibiotics (in particular oral antibiotics) should not be made available as OTC medicines as a matter of principle. In cases where antibiotics are assigned to OTC status, this should be done with great caution and following appropriate consideration of the potential risk of triggering cross-resistance to any other antibiotic with prescription indications. Moreover, measures should be in place to ensure patient safety and adequate monitoring of usage and antimicrobial resistance.

\section{Acknowledgements}

Funding sources had no role in the writing of this manuscript. The views in this article are the personal views of the authors. Those views may not be understood or quoted as being made on behalf, or reflecting the position, of the European Medicines Agency (EMA) or one of its committees or working parties.

\section{Conflict of interest}

None declared.

Authors' contributions

All authors contributed equally in the writing of the manuscript.

\section{References}

1. ReevesD. The 2005 Garrod Lecture: the changing access of patients to antibiotics--for better or worse?] Antimicrob Chemother. 2007;59(3):333-41. DOI: 10.1093/jac/dkl502 PMID: 17289771

2. AronsonJK. From prescription-only to over-the-counter medicines ('PoM to P'): time for an intermediate category. $\mathrm{Br}$ Med Bull. 2009;90(1):63-9. DOI: 10.1093/bmb/ldpo15 PMID: 19414447

3. European Commission. A guideline on changing the classification for the supply of a medicinal product for human use. Revision 2006. Bruxelles: European Commission. [Accessed Sep 2013]. Available from: http://ec.europa.eu/ health/files/eudralex/vol-2/c/switchguide_160106_en.pdf

4. Bond $C$. The over-the-counter pharmaceutical market-policy and practice. Eurohealth. 2008;14(3):19-24. Available from: http://www.euro.who.int/__data/assets/pdf_file/0016/80440/ Eurohealth14_3.pdf

5. BrassEP. Changing the status of drugs from prescription to over-the-counter availability.N Engl J Med. 2001;345(11):810-6. DOI: 10.1056/NEJMra011080 PMID: 11556302

6. Anekwe L. OTC antibiotic switch halted 'after Government opposition'. London: Pulse. 1 Apr 2010. Available from:http:// www.pulsetoday.co.uk/clinical/infectious-diseases/ chloramphenicol-use-remains-40-higher-due-to-otc-status/ on\%2ohttp:/www.pulsetoday.co.uk/otc-antibiotic-switchhalted-after-government-opposition/11028987.article\#. UXkC2MqUIWo

7. ECDC Antimicrobial Resistance and Healthcare-Associated Infections Programme,. Antibiotic resistance in Europe: the challenges ahead. Euro Surveill.2009;14(45):pii19405.

8. Council of the British Society for Antimicrobial Chemotherapy,BrownNM, PiddockLJ, DrydenMS. European Antibiotic Awareness Day and access to antibiotics.BMJ. 2012;19(345):e7819. DOI: 10.1136/bmj.e7819 PMID: 23166081

9. Price C. Chloramphenicol use remains $40 \%$ higher 'due to OTC status’. London: Pulse. 26 Apr 2013. Available from: http://www.pulsetoday.co.uk/clinical/infectious-diseases/ chloramphenicol-use-remains-40-higher-due-to-otcstatus/20002757.article

10. CarlstenA, WennbergM, BergendalL. The influence of Rx-to-OTC changes on drug sales. Experiences from Sweden 1980-1994.J Clin Pharm Ther. 1996;21(6):423-30. DOI: 10.1111/j.13652710.1996.tboo042.x PMID: 9201570

11. ScottG. Over the counter chloramphenicol eye drops.BMJ. 2010;340(feb26 1):C1016. DOI: 10.1136/bmj.C1016 PMID: 20189969

12. DavisH, MantD, ScottC, LassersonD, RosePW. Relative impact of clinical evidence and over-the-counter prescribing on topical antibiotic use for acute infective conjunctivitis. Br J Gen Pract. 2009;59(569):897-900. DOI: 10.3399/bjgpo9X473132 PMID: 20875257 
13. European Parliament (EP). European Parliament resolution of 11 December 2012 on the Microbial Challenge - Rising threats from Antimicrobial Resistance (2012/2041(INI)). Strasbourg: EP. 11 Dec 2012. Available from: http://www.europarl.europa.eu/ sides/getDoc.do? type $=$ TA\& reference $=$ P7-TA-2012-0483\&langu age $=$ EN \& ring $=A 7-2012-0373$

14. EuroVoc. Multilingual Thesaurus of the European Union. Domains and MT. 7206 Europe. Luxembourg: Publications Office of the European Union. [Accessed Sep 2013]. Available from: http://eurovoc.europa.eu/ drupal/?q=request\&mturi=http://eurovoc.europa.eu/100277\&l anguage $=$ en $\&$ view $=m t \&$ ifacelang $=e n$

15. MorganDJ, OkekeIN, LaxminarayanR, PerencevichEN, WeisenbergS. Non-prescription antimicrobial use worldwide: a systematic review.Lancet Infect Dis. 2011;11(9):692-701. DOI: 10.1016/S1473-3099(11)70054-8 PMID: 21659004

16. BoucherHW, TalbotGH, BradleyJS, EdwardsJE, GilbertD, RiceLB, et al. Bad bugs, no drugs: no ESKAPE! An update from the Infectious Diseases Society of America. Clin Infect Dis. 2009;48(1):1-12. DOI: 10.1086/595011 PMID: 19035777

17. SpellbergB, GuidosR, GilbertD, BradleyJ, BoucherHW, ScheldWM, et al. The epidemic of antibiotic-resistant infections: a call to action for the medical community from the Infectious Diseases Society of America. Clin Infect Dis. 2008;46(2):155-64. DOI: 10.1086/524891 PMID: 18171244

18. World Health Organization (WHO). Critically Important Antimicrobials For Human Medicine, 3rd revision 2011. Geneva: WHO. 2012. Available from: http://apps.who.int/iris/ bitstream/10665/77376/1/9789241504485_eng.pdf

19. Actavis UK Ltd. Clamelle. Devon: Actavis UK Ltd. [Accessed Sep 2013] Available from: http://www.clamelle.co.uk/

20. ScerriJ, MoneckeS, BorgMA. Prevalence and characteristics of community carriage of methicillin-resistant Staphylococcus aureus in Malta.J Epidemiol Glob Health. 2013;3(3):165-73. DOI: 10.1016/j.jegh.2013.05.003 PMID: 23932059

21. Medicines and Healthcare products Regulatory Agency (MHRA). Over-the-counter medicines, Reclassification, List of substances reclassified since 2002 , List C, Azithromycin. London: MHRA. [Accessed Aug 2015]. Available from: http:// webarchive.nationalarchives.gov.uk/20141205150130/ http://www.mhra.gov.uk/Howweregulate/Medicines/ Licensingofmedicines/Legalstatusandreclassification/ Listsofsubstances/index.htm\#l2

22. SafranyN, MonnetDL. Antibiotics obtained without a prescription in Europe.Lancet Infect Dis. 2012;12(3):182-3. DOI: 10.1016/S1473-3099(12)70017-8 PMID: 22361429

23. GrigoryanL, MonnetDL, Haaijer-RuskampFM, BontenMJ, LundborgS, VerheijTJ. Self-medication with antibiotics in Europe: a case for action.Curr Drug Saf. 2010;5(4):329-32. DOI: 10.2174/157488610792246046 PMID: 20615180

24. European Commission (EC). Special Eurobarometer 338. Antimicrobial Resistance Report. Brussels: EC. Apr 2010. Available from: http://ec.europa.eu/health/ antimicrobial_resistance/docs/ebs_338_en.pdf

25. BerzanskyteA, ValintelieneR, Haaijer-RuskampFM, GureviciusR, GrigoryanL. Self-medication with antibiotics in Lithuania.Int J Occup Med Environ Health. 2006;19(4):246-53. DOI: 10.2478 v10001-006-0030-9 PMID: 17402220

26. RossoliniGM, D’AndreaMM, MugnaioliC. The spread of CTXM-type extended-spectrum beta-lactamases.Clin Microbiol Infect. 2008;14(1) Suppl 1;33-41. DOI: 10.1111/j.14690691.2007.01867.x PMID: 18154526

27. KumarasamyKK, TolemanMA, WalshTR, BagariaJ, ButtF, BalakrishnanR, et al. Emergence of a new antibiotic resistance mechanism in India, Pakistan, and the UK: a molecular, biological, and epidemiological study. Lancet Infect Dis. 2010;10(9):597-602. DOI: 10.1016/S1473-3099(10)70143-2 PMID: 20705517

28. TängdénT, CarsO, MelhusA, LöwdinE. Foreign travel is a major risk factor for colonization with Escherichia coli producing CTXM-type extended-spectrum beta-lactamases: a prospective study with Swedish volunteers.Antimicrob Agents Chemother 2010;54(9):3564-8. DOI: 10.1128/AAC.00220-10 PMID: 20547788

29. AwadA, Eltayebl, MatoweL, ThalibL. Self-medication with antibiotics and antimalarials in the community of Khartoum State, Sudan.J Pharm Pharm Sci. 2005;8(2):326-31.PMID: 16124943

30. HadiU, DuerinkDO, LestariES, NagelkerkeNJ, WerterS, KeuterM, et al. Survey of antibiotic use of individuals visiting public healthcare facilities in Indonesia. Int J Infect Dis. 2008;12(6):622-9. DOI: 10.1016/j.ijid.2008.01.002 PMID 18396084

31. StellingJM, TraversK, JonesRN, TurnerPJ, O’BrienTF, LevySB. Integrating Escherichia coli antimicrobial susceptibility data from multiple surveillance programs.Emerg Infect Dis.
2005;11(6):873-82. DOI: 10.3201/eid1106.041160 PMID: 15963282

32. LesterSC, del Pilar PlaM, WangF, Perez Schaell, JiangH, O'BrienTF. The carriage of Escherichia coli resistant to antimicrobial agents by healthy children in Boston, in Caracas, Venezuela, and in Qin Pu, China.N Engl J Med. 1990;323(5):285-9. DOI: 10.1056/NEJM199008023230501 PMID: 2195344

33. Alliance for the Prudent Use of Antibiotics,. Executive summary: select findings, conclusions, and policy recommendations.Clin Infect Dis. 2005;41(4) Suppl 4;S224-7. PMID: 16032556

34. European Centre for Disease Prevention and Control (ECDC). Surveillance of antimicrobial consumption in Europe 2010. Stockholm: ECDC; Mar 2013. Available from:http://ecdc. europa.eu/en/publications/Publications/antimicrobialantibiotic-consumption-ESAC-report-2010-data.pdf 